\title{
Action crisis and cost-benefit thinking: A cognitive analysis of a goal-disengagement phase ${ }^{i s}$
}

\author{
Veronika Brandstätter ${ }^{\mathrm{a}, *}$, Julia Schüler ${ }^{\mathrm{b}}$ \\ a Department of Psychology, University of Zurich, Zurich, Switzerland \\ ' Institute of Sport Science, University of Berne, Berne, Switzerland
}

\begin{abstract}
A B S T R A C T
The present research is based on the notion that disengagement from goals is not a discrete event but a process (Klinger, 1975). A critical phase in this process is when difficulties and setbacks in striving for a goal accumulate. This critical phase is termed here as an action crisis. Given the profound effects that people's thoughts have on their self regulatory efficiency, it is essential to understand the cognitive correlates of an action crisis. In two experimental lab and two correlational field studies, the hypothesis that goal related costs and benefits become cognitively highly accessible during an action crisis was tested and supported. Participants who were experiencing an action crisis in such diverse goal areas as intimate relationships, sports, and university studies, thought about goal related costs and benefits more intensively and frequently in comparison to participants who were not in an action crisis. In an incidental learning task they recognized more of cost benefit items and less of implementation items than the control group. Results are interpreted in terms of action phase specific mindsets (Gollwitzer, 1990, 2012).
\end{abstract}

\section{Introduction}

Persistence in pursuing one's personal goals and disengagement from personal goals are two pivotal aspects of successful goal striving (Brandtstädter \& Rothermund, 2002; Carver \& Scheier, 2005; Klinger, 1977; Wrosch, 2011; Wrosch, Scheier, Carver, \& Schulz, 2003). On the one hand, without persistence individuals would never reach their goals. Hence, the capacity to resume goal directed action after tempo rary interruption and to tenaciously sustain it in the face of obstacles is crucial (Feather, 1962; Heckhausen, 1991). On the other hand, dis engagement from a goal may become badly necessary when striving

\footnotetext{
is We are grateful to Susanne Anrig, Lucia Horvath, Lisa Langer, Tabea Schwab, Marianne Steiner, and Bukurije Veseloski who ably assisted us in data collection. We would also like to thank Julius Kuhl for his valuable comments on an earlier version of this article. Parts of this research were funded by a grant from the Swiss National Science Foundation (SNSF) to Veronika Brandstätter (100014_130131).

* Corresponding author at: Department of Psychology, University of Zurich, Binzmühlestrasse 14/6, 8050 Zürich, Switzerland.

E-mail addresses: v.brandstaetter@psychologie.uzh.ch (V. Brandstätter), julia.schueler@ispw.unibe.ch (J. Schüler).
}

for the goal turns out to be unrealistic or too troublesome (Brandstätter, 2003; Brandtstädter, 2007; Brockner, 1992; Carver \& Scheier, 2005; Klinger, 1975; Kuhl, 1984; Staw, 1997; Wrosch, Scheier, Carver et al. 2003; Wrosch, Scheier, Miller, et al. 2003). There are many instances in all areas of life where people have diffi culty disengaging from a goal (e.g., continuing one's studies despite lack of interest and/or ability; investing in an unprofitable venture; remaining in an abusive relationship). Situational as well as intraper sonal factors might render a goal unattractive and/or unrealistic (Carver \& Scheier, 2005; Klinger, 1975), yet individuals might not be able to readily disengage from it which is associated with clear cut psychological and physiological impairments (Miller \& Wrosch, 2007; Wrosch, Amir, \& Miller, 2011; Wrosch, Miller, Scheier, \& de Pontet, 2007; Wrosch, Scheier, Miller et al., 2003).

Obviously, disengagement from a goal quite often seems to be a rath er difficult process as is aptly illustrated by Klinger's (1977) remark that it resembles a "psychic earthquake that will send shudders and rumbles through the person's life ..." (p. 137). Although several strands of re search show that the situation in which problems in goal striving accu mulate has implications for affective (goal progress and affect: Carver \& 
Scheier, 1981, 2005; goal disengagement failure and well being Wrosch et al., 2011, 2007), cognitive (goal frustration and rumination: Martin, Tesser, \& McIntosh, 1993), and behavioral (entrapment/ escalation of commitment in economic contexts: Brockner, 1992; Staw, 1997) processes, the dynamics of disengagement from personal goals is still not well understood. Especially, it is not known how the be ginning of the disengagement process appears. In the present paper we argue that the phase in which goal disengagement becomes an issue a specific cognitive orientation prevails.

In his seminal work on the dynamics of commitment to and disen gagement from incentives, Klinger $(1975,1977)$ was one of the first to deal with the issue of disengagement from personal goals. One of the central tenets of his analysis is that goal disengagement is not a binary event but rather a process that starts well before the individual definitively lets go of his/her goal. It is this phase of goal striving, when setbacks have accumulated and failures in making progress towards one's goal are becoming highly visible, that we are focusing on in the present paper and that we define as an action crisis. An action crisis is conceptualized as the phase in which the individual has already invested a great deal into his/her goal, encounters recur ring difficulties, and finally is caught between further goal pursuit and disengagement (cf. Carver \& Scheier, 2005). We deem it fruitful to have a closer look at this specific phase because it is inextricably intertwined with issues of goal disengagement.

The aim of the present analysis is to contribute to goal disengage ment research by establishing the concept of an action crisis as a critical and distinct phase in goal striving by scrutinizing its specific cognitive correlates. A cognitive analysis seems particularly promising as theories of self regulation agree about the assumption that the cog nitive representation of goal related concepts plays a pivotal role for self regulatory efficiency in goal striving (Carver \& Scheier, 2005; Förster, Liberman, \& Higgins, 2005; Gollwitzer, 1990; Goschke \& Kuhl, 1993; Kruglanski, 1996; Kuhl \& Kazén Saad, 1988; Marsh, Hicks, \& Bink, 1998; Martin \& Tesser, 1996; Vallacher \& Wegner, 1987). Accordingly, we intend to show that an action crisis is accom panied by a specific type of cognitive representation, namely cost benefit thinking. One of the most influential models for cognitive rep resentations in different phases of goal striving is the mindset theory of action phases (Gollwitzer, 1990, 2012; Heckhausen \& Gollwitzer, 1987) on which we base our line of reasoning.

\section{Action phases and mindsets}

The mindset theory of action phases (Gollwitzer, 1990, 2012; Heckhausen \& Gollwitzer, 1987) distinguishes distinct phases in the course of goal pursuit which are thought to be associated with specific tasks. On the one hand, the predecisional phase in which goal setting is pending, on the other hand the postdecisional phase which focuses on implementing the chosen goal. Accordingly, the predecisional phase involves weighing up the pros and cons of different action alter natives, whereas the postdecisional phase involves planning the neces sary action steps and finally acting on the goal for which the individual has opted.

The predecisional and postdecisional phases are postulated to be accompanied by specific cognitive orientations (mindsets) which are functional for solving the task at hand (i.e., setting a goal vs. implementing a goal). An impressive body of research has docu mented the distinct cognitive features of the so called deliberative (predecisional) and implemental (postdecisional) mindsets with re spect to thought content and characteristics of information processing (for a recent summary, see Gollwitzer, 1990, 2012). With respect to thought content, individuals who are about to take a decision on an ac tion alternative weigh up its pros (benefits) and cons (costs), whereas in individuals who are about to implement a goal focus on the concrete aspects of acting towards the goal (i.e., when, where and how to imple ment the goal), issues of costs and benefits are no longer relevant and thus are not cognitively represented (e.g., Heckhausen \& Gollwitzer, 1987). This core characteristic of the implemental mindset is clearly de scribed by Heckhausen (1991) who posits: "Once a goal intention has been formed, all thoughts are focused on its implementation ... Returning to thoughts about value and expectancy aspects of the cho sen goal would be disruptive ..." (p. 176). This cognitive tuning is con ceived of as a self regulatory mechanism which supports goal striving.

But what happens if goal striving is hampered, when difficulties and setbacks start to accumulate and the prospects for achieving the respective goal deteriorate, in short, when an action crisis prevails? In terms of the cognitive orientation, one would expect an action cri sis to expel an individual from the typical implemental mindset asso ciated with the postdecisional phase. But, would it put the individual back into a kind of deliberative mindset? The mindset theory of action phases remains silent about this.

There is plenty of literature suggesting that failure causes goal related rumination (e.g., Beckmann, 1998; Carver \& Scheier, 1981, 2005; Kuhl, 1981; Martin \& Tesser, 1989). A model that also deals with cognitive processes in different phases of action is Martin and Tesser's (1989) motivational theory of ruminative thought postulating a specific sequence of processes following the frustration of a goal (i.e., repetition of the instrumental behavior, attempting to find alternate routes to the goal, end state thinking, negotiation for goal abandon ment; cf. Klinger, 1975). Most importantly for our research, whenever the initial two phases are not successful, individuals should turn to end state thinking which "is likely to occur when individuals have dif ficulty in finding instrumental behaviors that will return them to the goal. At this stage, individuals think not about different ways of attaining the goal, but about the goal objects themselves" (Martin \& Tesser, 1989, p. 314). One way to think about a goal itself is in more su perordinate why terms (i.e., costs and benefits of further goal pursuit and goal disengagement, respectively) rather than in subordinate how terms (i.e., concrete goal directed behavior). Martin and Tesser (1996) characterize end state thinking to be the prototype of rumina tion, which appears to be non adaptive as the individual does not think about different ways of attaining or abandoning the goal, but cogitates about the goal's characteristics (i.e., its pros and cons). Thus, showing that an action crisis is associated with cost benefit thinking would be an important step towards elucidating the dynam ics of a critical phase in goal striving. Moreover, the theoretical scope of the mindset theory of action phases could be broadened by delin eating a specific mindset associated with an action crisis.

\section{The present research}

The present research was designed to test the hypothesis that indi viduals in an action crisis dwell on the costs and benefits of either con tinuing or ending goal striving. We conducted two experimental laboratory studies and two correlational field studies to test this hy pothesis with experimentally induced goals as well as with personal goals. The goals ranged from being in a close relationship (Study 1 ), and continuing one's major (Study 2) to going in for sports (Studies 3 and 4). In all of these studies, we compared a no action crisis group with an action crisis group with respect to cost benefit thinking. The action crisis was induced or measured, respectively, in various manners. In the two experimental studies, 1 and 2, we presented participants with a written description of a person confronted with an action crisis or not confronted with an action crisis. In Study 3, we used a question naire measure to assess the degree of action crisis with respect to a per sonal goal. Finally, in Study 4, we probed into the thought contents of marathon runners when passing kilometer 30 , which can be regarded as an objective instance of an action crisis. Likewise, cost benefit think ing was quantified in different ways: we asked our participants to rate the frequency and intensity of their cost benefit thinking (Studies 1 and 4), used a thought listing questionnaire (Study 3), or assessed memory performance in an incidental learning task (Study 2). 


\section{Study 1}

In our first study, we presented our participants with an everyday scenario which students were supposed to be familiar with. Thus, they should find it easy to identify with the protagonist and fully develop the mindset in question. Participants had to imagine them selves being in an intimate relationship that was either described as increasingly unhappy (action crisis) or as happy (no action crisis). Participants then had to rate the intensity of their cost benefit think ing. We hypothesized that action crisis participants would think more intensively about relationship related costs and benefits than no action crisis participants.

\section{Method}

\section{Participants and procedure}

Forty (20 females) students (mean age 24.6, range 2033 years) at a German university participated in the study. In a group session, participants first read a short scenario and then filled in a questionnaire.

\section{Scenario for induction of action crisis}

Participants were randomly assigned to one of two scenarios. Par ticipants in the action crisis condition were asked to imagine the fol lowing scenario:

Imagine that in your close relationship you are facing more and more problems. You feel bored in the presence of the other and you have only few common interests. Your partner is uncommuni cative and not very responsive to you. Sex has become unsatisfying. You have some hints that your partner has been unfaithful to you. Participants in the no action crisis condition were asked to imagine a situation where they were happy with their current close relation ship. All aspects of the relationship mentioned in the action crisis condition were described in a positive manner (e.g., no serious dissent, many common interests).

\section{Intensity of cost benefit thinking}

After reading the scenario, participants were told that people sometimes allowed their mind to wander, for example, when waiting for the bus. In such situations people would think about personally important issues. Participants were asked to put themselves in such a "waiting situation" and to think of their relationship as character ized in the scenario. After three minutes, participants were asked to rate on four items accompanied by five point scales $(1=$ not at all, $5=$ very much) the intensity with which they had thought of the costs $[\mathrm{CC}]$ and benefits of continuing the relationship $[\mathrm{BC}]$ as well as the cost $[C D]$ and benefits of disengaging from the relationship [BD], respectively. The types of costs and benefits were presented in two random orders (order 1 : benefit disengage $[\mathrm{BD}]$, benefit continue $[B C]$, cost continue $[C C]$, cost disengage $[C D]$; order $2: C C, B D, C D, B C)$.

\section{Scenario and manipulation checks}

Participants were asked about their identification with the scenario (e.g., "How well were you able to identify with the situation?"; "How well were you able to imagine yourself in the scenario?") using a five point scale ( $1=$ not at all, $5=$ very much). The two items were reli able $(\alpha=.87)$ and were aggregated in an index of mean ability to fantasize about the scenario. In addition, participants were shown four items covering the impulse to disengage from the relationship (e.g., "In that situation I would consider ending my relationship"; $\alpha=.95$ ). These items were used to create a mean index of disengage ment impulse.

\section{Results and discussion}

\section{Preliminary analyses}

There were no significant differences between the conditions in terms of the means, standard deviations, and correlations of the vari ables regarding gender and age. Controlling for gender and age in the following analysis did not affect any of the results.

\section{Scenario and manipulation checks}

Participants in both conditions (i.e., action crisis vs. no action crisis) were able to identify well with the scenario and no statistical difference existed between conditions with respect to this variable $\left(M_{\mathrm{ac}}=3.6, S D=1.1 ; M_{\text {no-ac }}=4.1, S D=.98 ; t(37)=1.60, p>.11\right)$. More importantly, the induction of an action crisis was successful as participants in the action crisis condition had a stronger disengage ment impulse $\left(M_{\mathrm{ac}}=3.6, S D=.91\right)$ than participants in the no action crisis condition $\left(M_{\text {no-ac }}=1.7, S D=.91 ; t(38)=6.63, p<.001\right)$.

\section{Testing the hypotheses}

\section{Intensity of cost benefit thinking}

In order to test the hypothesis that action crisis participants would think more intensively about relationship related cost benefits, a repeated measures ANOVA was computed with experimental condi tion (action crisis vs. no action crisis) and order of presentation (order 1 vs. order 2 ) as the between subject factors, and type of costs benefits (BC, CC, BD, CD) as the within subject factor. As the order of presentation of the cost benefit items had no effect on the results, it was omitted in the following analysis.

The analysis yielded significant main effects for condition, $F(1,38)=21.84, p<.001$, and for type of cost benefit, $F(3,114)=$ $14.12, p<.001$, which were qualified by a significant condition $x$ type of cost benefit interaction, $F(3,114)=5.41, p<.01$. As can be seen from Fig. 1, action crisis participants reported thinking signifi cantly more intensively about three of four cost benefit types com pared with no action crisis participants (Benefit Continue: $t<1$; Cost Continue: $t(38)=4.22, p<.001$; Benefit Disengage: $t(38)=1.54$, $p<.07$; Cost Disengage: $t(38)=4.99, p<.001$ ).

This result provides initial support for our hypothesis that an action crisis is accompanied by cost benefit thinking. Unexpectedly, differences between action crisis and no action crisis participants were not found for the benefits of continuing. One might speculate that the benefits of continuing are cognitively accessible even when everything is running smoothly (Oettingen \& Mayer, 2002), whereas the costs of continuing as well as the costs and benefits of disengaging from the goal only become accessible when goal striving difficulties accrue.

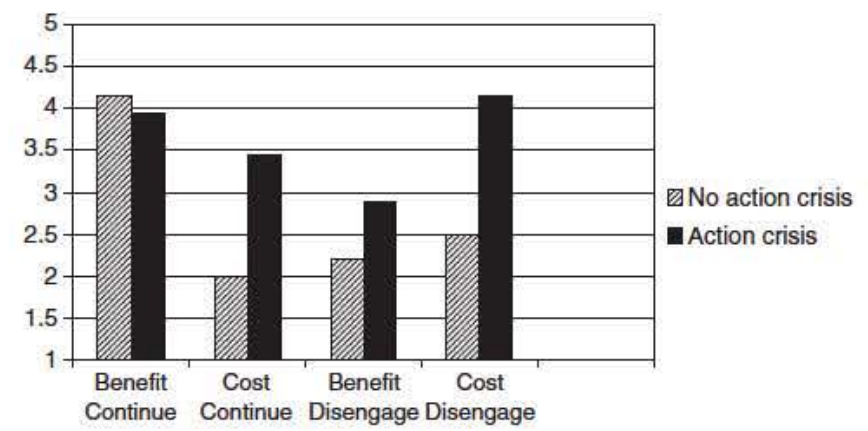

Fig. 1. Intensity of cost-benefit thinking in Study 1 by experimental condition. 


\section{Study 2}

Study 2 was designed to replicate Study 1 in a more rigorous manner. Instead of self report items, we used an incidental learning paradigm as an unobtrusive measure of cost benefit thinking. Addi tionally and even more importantly, we intended to show that the spe cific cognitive orientation (cognitive tuning) towards issues of goal implementation in the implemental mindset with a neglect of cost benefit issues is attenuated in an action crisis. With this in mind, we looked at the retention of cost benefit related material as well as of implementation related material.

In accordance with the mindset theory of action phases (Gollwitzer, 1990, 2012) we predicted a weaker relative memory advantage for implementation related over cost benefit related material in action crisis participants compared with non action crisis participants. Hence, in an incidental learning task, action crisis participants ought to recollect more cost benefit items and fewer implementation items than the control group participants (no action crisis).

The incidental learning technique is widely used to show processing (dis)advantages of specific contents (e.g., Nairne, Thompson, \& Pandeirada, 2007). In an incidental learning task, participants are asked to count a surface feature of verbal material and are then given a surprise retention test for the rated material. It is well known that in surface processing, highly activated semantic contents are recalled significantly better than non activated contents.

The induction of the action crisis was done by means of a written scenario describing a student who has either run into difficulties with his/her studies or for whom everything is working out well with his/ her studies. The scenario tapped into common instances of students' everyday life experiences. Hence we expected our participants to be familiar with these instances, and thus to find it easy to identify with the protagonist and fully develop a cognitive orientation associ ated with an action crisis or a situation in which no action crisis pre vails, respectively.

\section{Method}

\section{Participants and procedure}

Seventy ( 31 females) students (mean age 25, range 1943 years) at a Swiss university were recruited in lectures to participate in a study on empathy under cognitive strain. They received course credit for their participation. The study materials were processed in group sessions in a university classroom. First, participants read a two page scenario describing a student of their own gender in an action crisis or not in an action crisis. Participants were asked to identify as much as possible with the main character.

The action crisis scenario contained a description of a student facing increasing difficulties in his/her studies (e.g., s/he has already failed several exams; $s /$ he is not interested in the theoretical concepts taught in the undergraduate courses; his/her girlfriend/boyfriend does not support him/her in going to university). In the no action crisis condi tion, the same aspects were described in a positive manner. After that, participants answered several questions as manipulation and scenario checks.

Participants then conducted the incidental learning task. They were presented with 16 statements: eight statements containing cost benefit related information, eight statements containing implementation related information. Participants were asked to count the letter " $\mathrm{R} / \mathrm{r}$ " in each sentence and to write down the number as quickly and accurately as possible. After a filler task (i.e., mental arithmetic problems), all of a sudden a memory test was performed. In the recognition task, participants had to indicate which of 32 state ments ( 8 old cost benefit statements, 8 old implementation state ments, 8 new cost benefit statements, and 8 new implementation statements) had been included in the previous letter counting task.
Participants were then fully debriefed, and thanked for their participation.

\section{Scenario and manipulation checks}

Participants rated their agreement with two statements about their identification with the main character (i.e., "I could identify well with the main character."; "The situation is realistic.") using a five point scale $(1=$ not at all, $5=$ very much). The two items were sufficiently reliable taking into account that the two statements tapped different aspects of identification $(\alpha=.60)$ and were aggre gated in an index of mean identification. In addition, participants were presented with six statements assessing the action crisis of the protagonist (e.g., "S/he has no problems pursuing her/his studies"; "In her/his studies $s /$ he is repeatedly confronted with situations in which s/he does not know how to continue"). Participants rated their agreement on a five point scale $(1=$ does not apply at all, $5=$ applies completely). After recoding the respective items, the items were averaged to create a mean index of action crisis $(\alpha=.85)$.

\section{Incidental learning task}

16 statements referring to everyday goal directed behavior in the realm of university life, half relating to studies and half to sports and printed on a single page were presented to participants. Eight state ments referred to goal related costs and benefits, eight statements re ferred to the implementation of goal related activities. Of the eight cost benefit statements two statements referred to one specific type of goal related cost benefit (example from the field of sports: "If I continue exercising, I will be in good shape" [benefit continue, BC]; "If I continue exercising, I will suffer pain" [cost continue, CC]; "If I stop exercising, I can reduce my expenses" [benefit disengage, BD]; "If I stop exercising, I will feel more lonely" [cost disengage, $C D]$ ). The eight implementation related statements centered on the imple mentation of everyday activities (e.g., "When the training ends, I will have a shower"). Notably, none of these statements had appeared in the scenario text. We constructed two versions of the incidental learn ing material in order to prevent content effects due to a specific con stellation of cost benefit and content ${ }^{1}$. The participants' task was to count the letter " $\mathrm{R} / \mathrm{r}$ " in each statement as quickly and correctly as possible. The time participants needed for solving this task was recorded.

\section{Filler task}

To free working memory after the incidental learning task, partic ipants worked for four minutes on 38 taxing arithmetic problems.

\section{Memory test}

In the recognition test, 32 statements ( 8 old cost-benefit state ments, 8 old implementation statements, 8 new cost-benefit state ments, 8 new implementation statements, each category with 4 study items and 4 sports items) were presented in random order on two pages. Participants had to indicate whether or not a statement had occurred in the letter counting task, using a yes no format. Usual measures of recognition performance include hits and false alarms, which are combined into a single statistic known as $d^{\prime}$ that measures sensitivity (accuracy) as described below (Sahakyan \& Delaney, 2005; Stanislaw \& Todorov, 1999). We computed two recognition variables. "Hits" corresponded to saying yes to items that had been presented. "False alarms" corresponded to saying yes to non presented foils.

\footnotetext{
${ }^{1}$ For example, the BC item "If I continue exercising, I will be in good shape" was changed to "If I continue exercising, I will be in good company". The CC item "If I stop exercising, I will lose my good shape" was change into "If I stop exercising, I will have to spend time by myself again".
} 


\section{Results and discussion}

\section{Preliminary analyses}

No statistically significant differences occurred between women and men in the means of the measured variables and in the correla tions between them. Further, there were no statistical differences be tween the conditions regarding age.

\section{Scenario and manipulation checks}

Participants in both conditions were equally able to identify well with the scenario $\left(M_{\mathrm{ac}}=4.1, S D=.82 ; M_{\mathrm{no}-\mathrm{ac}}=4.1, S D=.47 ; t<1\right)$. More importantly, the induction of an action crisis was successful as participants in the action crisis condition ascribed a stronger action crisis $\left(M_{\mathrm{ac}}=3.8, S D=.47\right)$ to the protagonist than participants in the no action crisis condition $\left(M_{\mathrm{no}-\mathrm{ac}}=2.4, S D=.57 ; t(68)=10.94\right.$, $p<.001$ ).

\section{Letter counting and arithmetic problem tasks}

The experimental groups did not differ with respect to the time in seconds needed for the letter counting task $\left(M_{\mathrm{ac}}=143, S D=42.00\right.$; $\left.M_{\text {no-ac }}=159, S D=51.78 ; t(68)=1.36, p>.17\right)$, but did in terms of letter counting performance ${ }^{2}$ as action crisis participants showed a better performance than no action crisis participants $\left(M_{\mathrm{ac}}=11.8\right.$, $\left.S D=2.23 ; M_{\text {no-ac }}=10.1, S D=2.91 ; t(68)=2.81, \mathrm{p}<.01\right)$. There was no difference between groups with respect to the number of correctly solved arithmetic problems $\left(M_{\mathrm{ac}}=16.0, S D=5.20 ; M_{\mathrm{no}-\mathrm{ac}}=16.6\right.$, $S D=5.89 ; t<1)$.

\section{Testing the hypothesis}

\section{Recognition in memory test}

As a first step, we determined the absolute number of hits and false alarms for cost-benefit and implementation statements, re spectively, by conducting a 2 (types of statements: cost-benefit vs. implementation) $\times 2$ (response: hits vs. false alarms) $\times 2$ (action crisis: yes vs. no $) \times 2$ (version of incidental learning task) multivariate analysis of variance (MANOVA) with the first and second factors being within subject factors, and the third and fourth factors between subjects factors ${ }^{2}$. As there was no main effect for version of learning task $(F<1)$, and just one significant, though theoretically not relevant two way interaction between response, action crisis, and version of learning task $(p=.01$ ), we repeated the analysis omitting the factor ver sion of learning task.

This $2 \times 2 \times 2$ analysis yielded a significant main effect of response, $F(1,68)=225.03, p<.001$. Furthermore, we found a significant response $\mathrm{x}$ type of statements interaction, $F(1,68)=10.98, p=.001$, which was qualified by a response $\mathrm{x}$ type of statements $\mathrm{x}$ action crisis interaction, $F(1,68)=6.58, p=.01$. Table 1 displays the respective means and standard deviations. A first inspection of these results in dicates that in general participants produced more hits than false alarms. Moreover, on a descriptive level, it becomes evident that, as predicted, participants with no action crisis produced more hits and fewer false alarms for implementation statements compared with cost-benefit statements, a pattern which was reversed in action crisis participants, thus confirming the theoretical predictions.

In a second step, we put our hypothesis that action crisis participants would show a weaker relative memory advantage for implementation related over cost benefit related material compared with non action crisis participants to a test in terms of signal detection theory with its two basic concepts sensitivity $\left(d^{\prime}\right)$ and response bias (c) (Stanislaw \&

\footnotetext{
${ }^{2}$ The area of the statements (studies, sports) did not affect hits or false alarms in the recognition test, therefore, we did not include it as a factor in the analyses. As performance in letter counting did not correlate with memory performance we did not include it as covariate in the subsequent analyses.
}

Table 1

Means and standard deviations (in brackets) for hits and false alarms for cost-benefit and implementation statements by experimental condition in study 2 .

\begin{tabular}{llccc}
\hline & $\begin{array}{l}\text { Hits } \\
\text { cost-benefit }\end{array}$ & $\begin{array}{l}\text { Hits } \\
\text { implementation }\end{array}$ & $\begin{array}{l}\text { False alarms } \\
\text { cost-benefit }\end{array}$ & $\begin{array}{l}\text { False alarms } \\
\text { implementation }\end{array}$ \\
\hline No action crisis & $4.1(1.8)$ & $4.8(1.9)$ & $1.6(1.4)$ & $0.7(0.8)$ \\
Action crisis & $4.3(1.8)$ & $4.0(1.8)$ & $1.4(1.3)$ & $0.9(0.9)$ \\
\hline
\end{tabular}

Todorov, 1999). We calculated the respective indices for cost benefit statements $\left(d^{\prime}\right.$ co-be, $\left.c_{\text {co-be }}\right)$ and implementation statements $\left(d^{\prime}\right.$ impl, $\left.c_{\text {impl }}\right)$ according to Stanislaw and Todorov $(1999)^{3}$. We then created an index of sensitivity difference between cost benefit and implementation state ments using the formula $d^{\prime}{ }_{\text {co-be }}-d^{\prime}{ }_{\text {impl }}$ and an index of response bias dif ference using the formula $c_{\text {co-be }}-c_{\text {impl }}$. These sensitivity and response bias indices correlated with $r(70)=.39, p=.001$.

On this $d^{\prime}$ difference measure we conducted a 2 (action crisis: yes vs. no) $\times 2$ (version of incidental learning task) analysis of covariance (ANCOVA) with the relative response bias as the covariate and both fac tors as between subjects factors. The analysis yielded a significant main effect for action crisis $(F(1,65)=6.55, p=.01)$, no main effect for ver sion of incidental learning task $(F<1)$, and a non significant interaction between these factors $(F(1,65)=3.01, p=.09)$. In line with the theo retical predictions and unconfounded by individual differences in re sponse tendencies, action crisis participants $\left(M_{\mathrm{ac}}=-.19, S D=1.10\right)$ showed a significantly weaker advantage for implementation related over cost benefit related material compared with non action crisis participants $\left(M_{\text {no-ac }}=-.85, S D=1.28\right)$.

Identifying with a student suffering an action crisis as compared with identifying with a student not suffering an action crisis had a marked effect on recognition in an incidental learning task which represents cognitive accessibility of semantic contents. In both groups, there was a higher sensitivity for implementation statements, which is fully in accordance with the mindset theory of action phases. Most interestingly, however, as we had hypothesized, action crisis participants showed a significantly weaker memory advantage for implementation related over cost benefit related material in com parison to non action crisis participants. The different pattern in the action crisis vs. no action crisis groups supports the assumption that cognitive cost benefit related issues become more important in an action crisis relative to the usual cognitive orientation in the implemental phase of goal striving.

The results of Study 1 and Study 2 confirm the hypothesis about a specific cognitive feature of an action crisis, namely an increase of cost benefit thinking. Even though using scenarios in the first two studies allowed us to implement an experimental design, the scenario technique has a clear limitation. We do not know whether the results can be generalized to real goal striving situations since the goal striv ing described in the scenarios was of no personal importance to par ticipants. In order to remedy this shortcoming, we conducted two field studies asking participants about goals of personal importance with or without an action crisis. In view of this methodological change to real life goal striving, we adjusted the methodological pro cedure and used either a self report measure (Studies 3 ) or an objec tive instance (Study 4) of an action crisis. Moreover, we also used a different method of assessing cost benefit thinking.

\section{Study 3}

The aim of Study 3 was to test the hypothesis concerning cost benefit thinking in a real life situation where an individual is

\footnotetext{
${ }^{3}$ After determining the relative frequency of hits $(\mathrm{H})$ and false alarms (F) for costbenefit statements and implementation statements, the sensitivity index was calculated with the formula $d^{\prime}=\operatorname{PROBIT}(\mathrm{H}) \quad \operatorname{PROBIT}(\mathrm{F})$, whereas the index of response bias was calculated with the formula $c=.5 * \operatorname{PROBIT}(\mathrm{H})+\operatorname{PROBIT}(\mathrm{F})$.
} 
confronted with an action crisis when pursuing a personal goal. The participants were teenage members of the Swiss national table tennis team and were asked to report on their goal to become a successful top athlete. Cost benefit thinking was measured by asking partici pants to list the costs and benefits of continuing or abandoning their sports career, respectively, in a free response format (thought listing). We hypothesized that athletes confronting an action crisis would list more costs and benefits than athletes not confronting an action crisis.

\section{Method}

\section{Participants and procedure}

Twenty (10 females) members of the Swiss junior national table tennis team (mean age 15.9, range 1224 years) participated in the study during a weekend training camp. The athletes' mean training time was 10 (range 614.5 ) hours per week. During a break in the morning of the first day, participants were asked to complete the questionnaire.

\section{Action crisis}

The degree of action crisis was measured using the item "I have already thought about disengaging from competitive sports" accom panied by a seven point scale $(1=I$ do not agree at all; $7=I$ agree completely).

\section{Cost benefit thinking}

Participants were asked to think of their goal to become a high performance athlete. They were handed a thought listing sheet with four sections, one for each cost benefit type, and were asked to write down all the positive aspects (benefits) and negative aspects (costs) of being heavily involved in sports, as well as all the positive and negative aspects of disengaging from competitive sports.

\section{Results and discussion}

\section{Bivariate correlations and preliminary analyses}

No statistically significant differences occurred between women and men in the means of the measured variables and in the correla tions between them. Table 2 shows the means, standard deviations and zero order correlations of the main constructs.

Participants listed a mean of 2.83 (SD 1.35) goal related costs and benefits. In more detail, a repeated measures MANOVA on the listed number of costs/benefits yielded a significant effect of type of goal related costs/benefits, $F(2.13,40.5)^{4}=5.58, p<.01$. There was an overall tendency to report more benefits of continuing $(M=3.45$, $S D=1.79)$ and costs of disengaging $(M=2.95, S D=1.50)$ than costs of continuing $(M=2.40, S D=1.60)$ and benefits of disengaging $(M=2.50, S D=1.36)$ represented in a highly significant quadratic trend; $F(1,19)=16.77, p=.001$

\section{Testing the hypotheses}

In order to test our hypothesis, we looked at the correlations be tween degree of action crisis and the number of each of the four types of costs benefits. This analysis yielded a positive but non significant correlation coefficient for benefits of continuing $(r(20)=.24, p=.31)$, significant coefficients for costs of continuing $(r(20)=.46, p=.04)$ and benefits of disengaging $(r(20)=.61, p=.004)$, and a marginally significant coefficient for costs of disengaging $(r(20)=.41, p=.075)$.

\footnotetext{
${ }^{4}$ Mauchly's test indicated that the assumption of sphericity had been violated for the main effect of cost-benefit type $\left(\mathrm{Chi}^{2}(5)=13.36, p<.05\right)$. Therefore degrees of freedom were corrected using Greenhouse-Geisser estimates of sphericity $(\varepsilon=.71)$.
}

Table 2

Bivariate correlations between study variables in study 3 .

\begin{tabular}{|c|c|c|c|c|c|c|c|c|}
\hline & & 2 & 3 & 4 & 5 & 6 & $M$ & $S D$ \\
\hline 1 & Action crisis & .24 & $.46^{*}$ & $.61^{* *}$ & $.41+$ & .15 & 3.55 & 2.37 \\
\hline 2 & Benefit continue & & $.85^{* *}$ & $.64^{* *}$ & $.50^{\circ}$ & .20 & 3.45 & 1.79 \\
\hline 3 & Cost continue & & & $.82^{* \bullet}$ & $.59^{* *}$ & .33 & 2.40 & 1.60 \\
\hline 4 & Benefit disengage & & & & $.63^{* *}$ & .15 & 2.50 & 1.36 \\
\hline 5 & Cost disengage & & & & & .10 & 2.95 & 1.50 \\
\hline 6 & Gender & & & & & & - & - \\
\hline
\end{tabular}

Note. $N=20$. Coding for gender: $1=$ male, $2=$ female.

$+p<.10 .{ }^{*} p<.05 .^{* *} p<.01$.

As we had predicted, overall, young athletes who experienced an action crisis listed more costs of continuing, as well as benefits and costs of disengaging from competitive sports than young athletes not in an action crisis. Unexpectedly, action crisis did not relate to the number of benefits of continuing the goal in question as was already the case in Study 1 .

Hence, the relationship between action crisis and cost benefit thinking was replicated for the area of personal goal striving in the context of sports. Notably, in contrast to Studies 1 and 2, participants in the present study reported costs and benefits with respect to a per sonal goal of high personal importance. Nevertheless, we obtained the same pattern of results.

In this study we operationalized an action crisis by the degree to which an individual had ever felt an impulse to disengage from the respective personal goal. An impulse to disengage from an ongoing goal is theorized to be a core aspect of an action crisis. As long as a goal pursuit flows smoothly, an individual would never think of letting go the goal. Through recurring setbacks, a situation arises in which the individual is caught between further goal pursuit and disengagement both options are within reach, which causes an intra psychic conflict. With this we wanted to tap into an action crisis at a point in time when, after repeated setbacks, the individual pre sumably starts to consider the option of goal disengagement.

This study for the first time provides empirical evidence that deci sional conflicts embedded in the actional phase are governed by the same principles as decisional conflicts when confronted with choos ing a goal or not (goal setting). It would have been well conceivable that individuals who are facing difficulties in their goal pursuits and because of that are experiencing a goal disengagement impulse rumi nate about the causes of their failure (Weiner, 1985), about strategies to overcome the difficulties (Gollwitzer \& Sheeran, 2006) or even suppress any thoughts directed at the goal in question in order to dis tract from the unpleasant situation (Gross \& Thompson, 2007).

\section{Study 4}

Marathon runners concordantly report that they often experience a caving in of their physical as well psychological resources around the 30 kilometer mark, colloquially described as "running into a wall". Physiologically there is a change from glucose to fat burning which is accompanied by a temporary but heavy loss of energy (Martin \& Coe, 1997; Stevinson \& Biddle, 1998). Some quotes may illustrate the related subjective experience of athletes: "I became slightly dizzy and my legs did not seem to want to obey me anymore"; "I felt totally drained. I had no strength left."; "I had to struggle with myself." In our view, what marathon runners experience in the section around kilometer 30 clearly represents an action crisis. When they start the marathon race, athletes feel energetic and fully concentrated on their goal of finishing the race. By and by, physical resources are drained, and often failure to keep up one's speed is experienced, most obviously when approaching kilometer 30 .

Hence, a marathon race offers an excellent opportunity to tap into the process dynamics of a naturally occurring action crisis. We there fore asked our participants about their impulse to disengage from 
the goal to run the marathon and about their cost benefit related

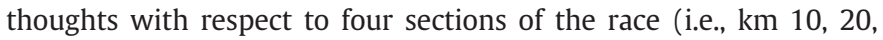
30 , and 40 ).

We hypothesized that between $\mathrm{km} 10$ to $\mathrm{km} 30$ athletes would experience an increasing impulse to disengage from the goal to run the marathon, and then again a decreasing disengagement impulse toward $\mathrm{km} 40$ which is very close to the finish of the race. Likewise, it was predicted that marathon runners would think about goal related costs and benefits most around $\mathrm{km} 30$, with the least cost benefit thinking around $\mathrm{km} 10$, increasing cost benefit thinking around $\mathrm{km} \mathrm{20}$, and decreasing cost benefit thinking at $\mathrm{km} 40$. Further, we reasoned that the specific cognitive mindset in an action crisis would not only become evident in terms of a higher frequency of cost benefit thoughts but also in an increasingly unordered and rapidly changing flow of thoughts (Beckmann, 1998). Accordingly, we hypothesized that cost benefit related thought should become

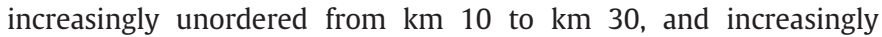
ordered again around $\mathrm{km} 40$.

\section{Method}

\section{Participants and procedure}

One hundred and fourteen (38 females) non professional mara thon runners (mean age 36.8, range 1862 years) volunteered for participation and received a take home booklet which they were asked to fill out after their race and to send back as soon as possible. They had a mean experience in long distance running of 7.5 years (range 1 to 30 years) and they were running a mean weekly distance of $52.0 \mathrm{~km}$ (range 17 to $100 \mathrm{~km}$ ). One participant was excluded from the analyses who indicated a weekly running distance of $260 \mathrm{~km}$ which is more than three standard deviations above the mean run ning distance of the sample.

\section{Material}

The take home booklet contained questions referring to a disen gagement impulse, cost benefit thinking, and disorder of thoughts. These aspects were assessed with respect to four sections of the race (kilometer 10, 20, 30 and 40). Participants were helped to imagi ne these sections by a vivid description of the respective surround ings (e.g., distinctive buildings, names of streets).

\section{Disengagement impulse}

Disengagement impulse was measured using two questions that were averaged ("To what extent did you experience the impulse to give up your race?"; "How often did you think: 'I will have to give up now'?" Correlations for the four measurement points, $.39<r s(114)<.89, p s<.001)$. Answers were given on a seven point scale $(1=$ not at all, $7=$ very much $)$.

\section{Cost benefit thinking}

For each race section, participants had to indicate how frequently they had thought of goal related costs and benefits of running further (not running further) $(1=$ never, $5=$ very frequently). The order of costs and benefits of goal striving and disengagement was counterbalanced across participants.

\section{Disorder of thought}

Additionally, on a five point scale $(1=$ does not apply, $5=$ does fully apply) participants answered four statements with respect to the disorder of their thoughts (e.g., "My thoughts went to and fro chaotically"). These were averaged for each section of the race to form an index of disorder of thought (Cronbach's alphas, $\mathrm{km} 10=$ $.62, \mathrm{~km} \mathrm{20}=.82, \mathrm{~km} \mathrm{30}=.82, \mathrm{~km} 40=.76)$.

\section{Results and discussion}

\section{Bivariate correlations and preliminary analyses}

There were no systematic statistically significant differences be tween women and men in the means of the measured variables ${ }^{5}$ and in the correlations between them. For each type of cost benefits, fre quency of thinking was significantly correlated between the four sec tions of the race $(.24<r<.63)$ with two exceptions $\left(r_{\mathrm{CC}-10, \mathrm{cc}-30}=.06\right.$, $\left.r_{\mathrm{BD}-10, \mathrm{BD}-30}=.14\right)$. Disorder of thought also was significantly correlated between the four sections of the race $(.37<r<.61)$. For disengagement impulse there were two significant correlations between different sections of the race $\left(r_{\text {DIS-20, DIS-30 }}=.38, r_{\text {DIS-30, DIS-40 }}=.31\right)$. Table 3 shows the means, standard deviations and zero order correlations of the main constructs that were aggregated across sections of the race.

\section{Testing the Hypotheses}

\section{Disengagement impulse}

A repeated measures ANOVA on the disengagement impulse index

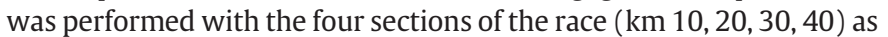
the within subjects factor which had a significant effect, $F(3,336)=$ $26.98, p<.001$, indicating that strength of disengagement impulse dif fered between sections of the race. By inspecting the means $\left(M_{10}=\right.$ $1.1, S D=.23 ; M_{20}=1.6, S D=1.25 ; M_{30}=2.2, S D=1.5 ; M_{40}=1.4$, $S D=.90)$ it becomes evident that, as hypothesized, the disengage ment impulse increased monotonically from $\mathrm{km} 10$ to $\mathrm{km} 30$ and then dropped again, resulting in a highly significant quadratic trend, $F(1,112)=41.47, p<.001$. This result validates our assumption re garding the process of a naturally arising action crisis when marathon runners face the so called "wall" at km 30.

\section{Frequency of cost benefit thinking}

In order to test the hypothesis that the frequency of cost benefit thinking would be highest at $\mathrm{km} \mathrm{30}$, a repeated measures ANOVA was performed with the two within subjects factors, section of race

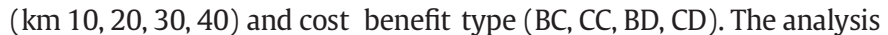
yielded significant main effects for section of race, $F(2.76,309.07)^{6}=$ 47.08, $p<.001$, as well as for cost benefit type, $F(1.81,202.60)=$ $147.22, p<.001$. These main effects were qualified by a significant sec tion of race by cost benefit type interaction, $F(5.90,660.49)=10.82$, $p<.001$. To break down the interaction, specific pairs of cost benefit types were contrasted across sections of race. This revealed sig nificant interactions for the quadratic trend when comparing benefits of continuing and costs of continuing, $F(1,112)=16.22, p<.001$, and when comparing benefits of disengaging and costs of disengaging, $F(1,112)=11.48, p<.001$. The remaining contrast revealed no signifi cant interaction term when comparing benefit of continuing and bene fit of disengaging across sections of race. Inspecting Fig. 2, it becomes evident that, as predicted, the frequency of cost benefit thinking shows a marked increase from $\mathrm{km} 10$ to $\mathrm{km} \mathrm{30,} \mathrm{and} \mathrm{again} \mathrm{a} \mathrm{significant}$ decrease from $\mathrm{km} 30$ to $\mathrm{km} 40$ for cost of continuing, benefit of disengaging, and cost of disengaging as reflected by significant qua dratic trends. For benefit of continuing, the pattern is different. First, athletes overall thought more frequently about the benefit of

\footnotetext{
${ }^{5}$ There was a significant difference between men $(\mathrm{M}=2.4 \mathrm{SD}=1.2)$ and women $(\mathrm{M}=1.7, \mathrm{SD}=.87$ ) with respect to the frequency of thought related to the costs of running further at $\mathrm{km} 30 ; \mathrm{t}(97.95)=3.57, \mathrm{p}<.01$. Also, men $(\mathrm{M}=2.5 \mathrm{SD}=1.6)$ and women $(\mathrm{M}=1.7 \mathrm{SD}=1.0)$ differed with respect to the felt disengagement impulse at $\mathrm{km} 30$; $\mathrm{t}(108.3)=3.06, \mathrm{p}<.01$.

${ }^{6}$ As Mauchly's test was significant for the main effects of section of race $\left(\mathrm{Chi}^{2}(5)=14.05, p<.05\right)$ and cost-benefit types $\left(\mathrm{Chi}^{2}(5)=163.18, p<.001\right)$ as well as for the interaction effect between both $\left(\mathrm{Chi}^{2}(44)=282.08, p<.001\right)$, degrees of freedom were corrected using Greenhouse-Geisser estimates of sphericity $(\varepsilon=.92$ for the section of race main effect, $\varepsilon=.60$ for the cost-benefit type main effect, and $\varepsilon=.66$ for the interaction)
} 
Table 3

Bivariate correlations of variables in study 4 .

\begin{tabular}{|c|c|c|c|c|c|c|c|c|c|c|}
\hline & & 2 & 3 & 4 & 5 & 6 & 7 & 8 & M & $S D$ \\
\hline 1 & $B C$ & $.45^{\circ * *}$ & $.41^{* *}$ & $.55^{\circ \cdots *}$ & $37^{* * *}$ & $.29^{\circ *}$ & .01 & .18 & 2.98 & 1.15 \\
\hline 2 & $\mathrm{CC}$ & & $86^{* * *}$ & $.65^{* * *}$ & $.53^{* \cdots}$ & $.73^{* * *}$ & .15 & $31^{* *}$ & 1.64 & .62 \\
\hline 3 & BD & & & $60^{* * *}$ & $.57^{* * *}$ & $.80^{* * *}$ & .08 & $34^{* *}$ & 1.53 & .59 \\
\hline 4 & $\mathrm{CD}$ & & & & $.44^{* * *}$ & $.49 * *$ & .04 & $28^{* *}$ & 1.81 & .85 \\
\hline 5 & DOT & & & & & $.58^{* * *}$ & .01 & $22^{*}$ & 1.98 & .62 \\
\hline 6 & DIS & & & & & & .09 & $36^{* * *}$ & 1.59 & .67 \\
\hline 7 & Gender & & & & & & & .14 & - & - \\
\hline 8 & RUN & & & & & & & & 52.01 & 17.45 \\
\hline
\end{tabular}

Note. $N=95-113, B C=$ benefits continue across sections of race, $\mathrm{CC}=$ costs continue across sections of race, $\mathrm{BD}=$ benefits disengage across sections of race, $\mathrm{CD}=$ costs disengage across sections of race, DOT=disorder of thought, DIS=disengagement impulse, RUN = weekly running hours. Coding for gender: $1=$ male, $2=$ female. ${ }^{*} p<.05$. "* $p<.01 .{ }^{* * *} p<.001$

continuing than the cost of continuing, the benefit of disengaging, and the cost of disengaging; and second, there was no decrease in the frequency of thinking from $\mathrm{km} 30$ to $\mathrm{km} 40$.

\section{Disorder of thought}

To test the hypothesis that disorder of thought would be highest at $\mathrm{km} 30$ a repeated measures ANOVA (within subject factor: section of

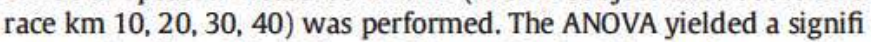
cant main effect, $F(3,336)=16.95, p<.001$. Looking at the respective means $\left(M_{10}=1.7, S D=.65 ; M_{20}=1.9, S D=.81 ; M_{30}=2.2, S D=.87\right.$; $\left.M_{10}=2.1, S D=.81\right)$ it becomes evident that, as hypothesized, the dis

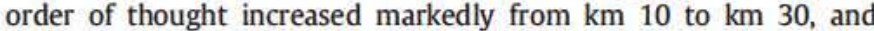
dropped again slightly resulting in a marginally significant quadratic trend, $F(1,112)=3.75, p<.06$.

In Study 4 , cost benefit thinking was analyzed in a marathon race which offered an excellent opportunity to observe how an action cri sis develops. With this we complement the analyses of Studies 1 to 3 that cross sectionally focused on one point in time when participants either imagined or reported suffering an action crisis or not. In Study 4, as predicted, not only did the frequency of cost benefit related thought steadily increase from the beginning of the marathon race to the most critical section of the race (i.e., $\mathrm{km} 30$ ), but also thoughts became maximally unordered at $\mathrm{km} 30$. Both higher frequency of thought and a higher degree of disorder of thoughts are aspects of rumination caused by difficulties in goal striving (Beckmann, 1998).

The assessment of the cognitive processes at the four sections of the race was done retrospectively. However, by furnishing our participants with a concrete description of the respective surroundings at $\mathrm{km} \mathrm{10,20}$ 30 and 40 , we provided them with specific cues for recall which pro moted a reliable report of their actual cost benefit thoughts.

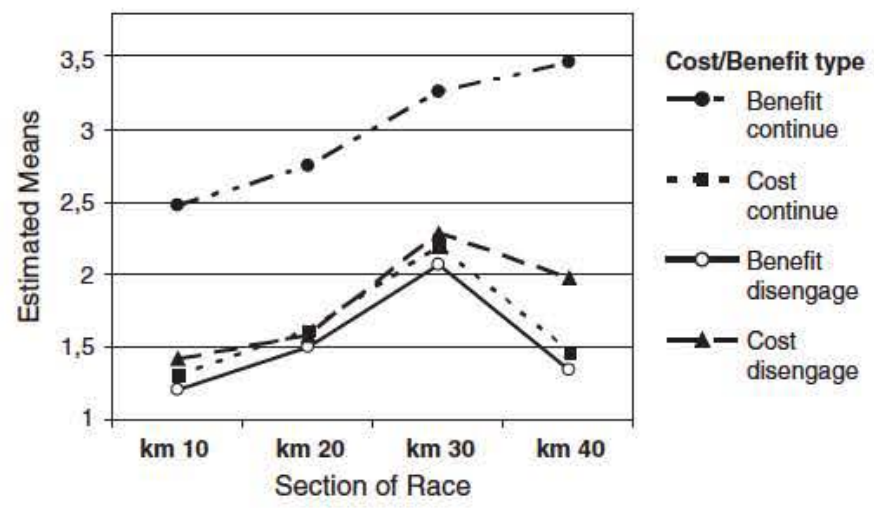

Fig. 2. Frequency of cost-benefit thinking across four sections of marathon race in Study 4.
In Study 4, we were again interested in the cognitive processes in an action crisis and not in behavioral outcomes per se (i.e., persis tence vs. disengagement from goal pursuit). Besides, we do not posit that an action crisis necessarily leads to goal disengagement. It is perfectly conceivable that the individual will recover his/her implemental mindset and that the goal will gain new momentum. The exact processes that determines further persistence vs. goal dis engagement are open to further research.

\section{General discussion}

We devoted our attention to a phenomenon closely associated with issues of goal disengagement, namely circumstances in which an individual confronts continuing difficulties and setbacks in striving for a goal. We have termed this instance an action crisis. We were in terested in cognitive correlates of an action crisis and postulated that experiencing an action crisis would change the cognitive orientation and dampen the firm resolution for goal achievement that is typical of the implemental mindset. More specifically, we hypothesized that individuals who experience an action crisis would be shifted into a deliberative mindset (Gollwitzer, 1990, 2012), that is, think more about goal related costs and benefits than individuals who do not experience an action crisis. We tested this assumption in two experi mental (Studies 1 and 2) and two correlational studies (Studies 3 and 4 ) focusing on goals from different areas of life (e.g., intimate relationship, academic concerns, sports). In all four studies we com pared individuals in an action crisis with individuals not in an action crisis with respect to cost benefit thinking. In doing so, we actualized different instances of an action crisis (i.e., scenario describing an indi vidual in an action crisis, measuring an actual action crisis with a real personal goal, and an objective instance of an action crisis).

We also used different methods of assessing cost benefit thinking. We either asked respondents to give a retrospective assessment of the extent (frequency, intensity) to which they had thought about the spe cific goal related costs and benefits in the recent past (Studies 1, 4; cf. Martin \& Tesser, 1989), asked them to list all current costs and benefits of their goal (Study 3), or we used an incidental learning paradigm to capture the accessibility of cost benefit in comparison to implemen tation related material (Study 2; cf. Sahakyan \& Delaney, 2005; Wattenmaker, 1999). Thus, we did not only obtain the predicted pattern of results with a retrospective focus but also when participants reported on current costs and benefits.

Despite this methodological heterogeneity, the pattern of results is very consistent across the studies, which argues for its generaliz ability. The data strongly confirm our hypothesis that participants who were instructed to identify with another person experiencing an action crisis thought about goal related costs and benefits more intensively (Study 1 ) and in a memory test they recalled more cost benefit related statements and less implementation related state ments than participants not identifying with a person in an action crisis (Study 2). Also, participants who were themselves experiencing an action crisis, listed more personally relevant costs and benefits (Study 3 ) and thought more frequently about them (Studies 4 ), than participants not experiencing an action crisis. This was true for all types of goal related costs/benefits but most pronounced for costs of continuing, benefits of disengaging, and costs of disengaging. Benefits of continuing were cognitively represented equally in action crisis and no action crisis participants (with an exception in Study 3). Obviously, the benefits of continuing are cognitively accessible even if goal striving is going smoothly since they represent the final objective of goal striving (Klinger, 1977; Oettingen \& Mayer, 2002). By contrast, the other three cost benefit types (cost of continuing, benefit of disengaging, cost of disengaging) seemingly come into play mainly when goal striving runs into problems.

Most importantly, by using an incidental learning paradigm in Study 2 we can preclude the possibility that the observed effect of 
an action crisis on cost benefit thinking is due to the self report format by asking participants how frequently or intensively they were thinking about goal related costs/benefits. Moreover, this clearly rules out the alternative explanation that our results are based solely on lay beliefs about goal striving and disengagement, which could play a certain role when individuals report on their cognitive processes in a questionnaire.

Moreover, in Study 2 we not only presented cost benefit related ma terial to our participants, but also implementation related material. Our results show that in no action crisis participants there was a markedly higher difference between cognitive accessibility of implementation related material and cost benefit related material which perfectly cor responds to the cognitive characteristics of the implemental mindset in unproblematic goal striving (Gollwitzer, 1990; 2012). In action crisis participants, however, the dominance of cognitive accessibility of implementation related material over cognitive accessability of cost benefit related material was markedly attenuated. This result strengthens the assumption of a distinct cognitive mindset in people facing an action crisis in their goal striving in comparison to those who do not.

In our studies we focused on the cognitive representation of goal related costs and benefits in the postdecisional (implemental) phase. Interestingly, the role of cost benefit thinking in the postdecisional (implemental) phase of goal striving was also ana lyzed by Nenkov and Gollwitzer (2012). They had participants who were committed to a goal elaborate on the pros (benefits) and cons (costs) of the respective goal. Their findings show that assigned delib eration on a goal strengthens goal commitment. The authors explain this effect as follows: "[The] postdecisional mindset is associated with a cognitive orientation that facilitates the implementation of the chosen goal, postdecisional individuals have easy access to the cognitive procedures that promote holding on to a partial analysis, even when even handed deliberation is requested. As a result, with postdecisional deliberation a defensive focus on the pros of goal pur suit should prevail and the commitment to the chosen goal should be strengthened" (p. 3). It would be interesting to investigate whether, under what conditions, and how cost benefit thinking in an action crisis also increases commitment to the goal in question thus leading to a kind of "escalation of commitment" situation.

\section{Theoretical implications of the present research}

Our research contributes to the understanding of goal striving and goal disengagement in two important ways. A first theoretical advance of our research lies in its fine grained analysis of the cognitive processes when goal striving is thwarted. Our studies go beyond the previous work on cognitive correlates of unfulfilled goals by focusing on cogni tive contents that represent the motivational source of goal striving. More specifically, goal related costs and benefits constitute the incen tives for goal related behavior (Beckmann \& Heckhausen, 2008), that is, the anticipated consequences of striving for a goal or disengaging from it, respectively, and with this they point at the "why" of behavior (Trope \& Liberman, 2010; Vallacher \& Wegner, 1987).

More importantly, though, our theorizing widens the scope of the mindset theory of action phases (Gollwitzer, 1990, 2012; Heckhausen \& Gollwitzer, 1987) which does not address the issue of cognitive representations in instances when the implementation of a goal becomes problematic. As our results show, an action crisis is asso ciated with a preponderance of goal related cost benefit thoughts. Obviously, an action crisis expels an individual from the typical implemental mindset. The possibility of a mindset shift has not been discussed in the existing mindset literature so far. The present re search addresses an important condition of such a mindset shift, namely negatively valenced events related to setbacks and failures in the pursuit of a personal goal. But would positive events, for example, an unexpectedly easy progress towards the goal, or the appearance of a highly attractive alternative, also lead an individual to deliberate anew on the costs and benefits of his/her goal? Another interesting re search question would be whether a deliberative mindset embedded in the implemental phase of goal striving is of a different nature to the deliberative mindset before taking a decision. That is, would the former be likewise associated with an unbiased and realistic process ing of desirability and feasibility information? Or, would it rather carry characteristics of biased information processing, as it is typical for the implemental mindset? An answer to these questions could tell us something about the functional value of the mindset shift.

From a functional point of view, on the one hand, thinking about goal related costs and benefits in the phase of goal implementation seems problematic. It might bring to consciousness a conflict between opposing behavioral tendencies, especially when the costs of continuing and the costs of disengaging seem roughly equal (Mann \& Janis, 1982). This constellation represents a typical form of an avoidance avoidance conflict (Lewin, 1951) which can leave the individual "entrapped" (Brockner, 1992; Staw, 1997) as decision making in conflict situations is more difficult than in non conflict situations (Diederich, 2003; Miller, 1944; Tversky \& Shafir, 1992). Besides, focusing on goal related costs and benefits might prevent the individual from finding good strat egies to solve the problems encountered and thus lead to an aggravation of the action crisis (Martin \& Tesser, 1989).

On the other hand, however, there might also be some self regulatory assets of cost benefit thinking in an action crisis. Re deliberating the costs and benefits of a goal which has turned sour might open one's mind to possible alternatives and thus help the individual to disengage from the goal in question. Moreover, con sidering costs/benefits of continuing/disengaging from a goal may also be embraced in order to motivate oneself to envision the why of one's behavior.

All things considered, an action crisis does not necessarily lead to goal disengagement; it is quite conceivable that the individual will re cover his/her implemental mindset and the goal will thus gain new momentum. The exact processes that decide on further persistence vs. goal disengagement are open to further research.

Second, our research extends work on goal disengagement by Wrosch, Scheier, Carver, et al., (2003) Wrosch, Scheier, Miller, et al., (2003) Wrosch et al. (2007) who have shown that an individual's lack of goal adjustment capacities (e.g., difficulties in disengaging from an unattainable goal) leads to psychological and physical impair ments. With our research we have gone one step further to shed light on the cognitive processes that might be related to these affective cor relates and their roots in personality differences. Obviously, in an ac tion crisis a conflict results from the fact that either option is associated with costs and benefits, the balance of which neither clearly suggests further goal pursuit nor clearly suggests goal disengagement (Brockner, 1992; Mann \& Janis, 1982; Staw, 1997). Indeed, in terms of face validity, in Studies 1, 3, and 4 the ratio between incentives for continuing (i.e., $\mathrm{BC}$ and $\mathrm{CD}$ ) and incentives for disengaging (i.e., $\mathrm{CC}$ and $\mathrm{BD})$ is lower in the action crisis condition $(1.3,1.2,1.3)$ than in the no action crisis condition $(1.6,1.5,1.6)$ which is a clear indication of a stronger conflict in the former condition. Furthermore, for exam ple, Emmons and King (1988) have shown that goal related conflict has significant emotional costs.

\section{Limitations and future directions}

First, we asked our participants how frequently or how intensively they had thought about costs/benefits in the past, or by presenting them with these aspects in an incidental learning task. In future studies, still more unobtrusive measures could be used to assess cost benefit thinking, for example, by subliminally presenting participants with cost benefit related material in the manner of an implicit association test (Greenwald, McGhee, \& Schwartz, 1998). Another avenue could 
be to use an experience sampling method to tap into the continuous stream of conscious thought (e.g., H. Brandstätter, 2007).

Second, we focused solely on cognitive aspects of an action crisis. However, this neglect of the emotional aspects of action crises and goal disengagement in the present research should not obscure the fact that action crises can be highly negative emotional events in goal striving (Carver \& Scheier, 2005; Heckhausen, Wrosch, \& Schulz, 2010; Klinger, 1975; Wrosch, Scheier, Carver et al. 2003; Wrosch, Scheier, Miller et al. 2003). Future research ought to look at affective and physiological correlates of an action crisis on the level of concrete personal goals. This would complement the theorizing by Wrosch and colleagues, who focus on the relationship between goal adjustment capacities conceptualized as an individual difference variable and affective outcomes. Also, it is necessary to scrutinize the interplay between affect and cognitive processes in an action crisis (e.g., Forgas, 1995).

Third, in Study 4 we looked at the evolution of an action crisis in a marathon race that only lasted at most about 4 hours. Longitudinal studies over a longer period of time are desirable in order to gain more information on the development of an action crisis in personal goals. This would also allow for a test of the self regulatory implica tions of cost benefit thinking. Brandstätter, Schüler, and Frank (2008) have provided evidence from a field experiment that mentally focusing on specific goal related costs and benefits has a significant effect on behavior. These results open up possibilities for an interven tion to help people to disengage from unattainable goals. Moreover, a longitudinal design would allow for a clarification of the causal role of an action crisis for cost benefit thinking in everyday contexts and possible reciprocal effects between experiencing an action crisis lead ing to cost benefit thinking which in turn aggravates the action crisis. Also, in future studies one should experimentally induce an actual ex perience of an action crisis and combine this with an unobtrusive measure of its cognitive correlates. This would circumvent the prob lem generally associated with the scenario method used in Studies 1 and 2, where lay theories about cognitive processes could play a certain role.

Fourth, our data do not tell anything about the role of cost benefit thinking for ultimate goal disengagement or goal reengagement (Wrosch, Scheier, Carver et al. 2003; Wrosch, Scheier, Miller et al. 2003). In future studies one definitely might want to scrutinize the relationship between cost benefit thinking and goal disengagement or goal reengagement. As James (1890) put it: "My thinking is first and last and always for the sake of my doing" (p. 333) the cognitive side of an action crisis should definitely be related to the behavioral side of an action crisis.

A fifth important issue for a future research agenda is the role of indi vidual differences in the inclination to experience an action crisis. State oriented individuals are "more rigidly attached to a goal even after repeatedly failing to reach it and less inclined to replace an unattainable goal by some substitute goal" (Kuhl, 1981, p. 161; see also Jostmann \& Koole, 2009). Accordingly, one should analyze whether state oriented individuals are more prone to experience an action crisis and tend more to cost benefit thinking than action oriented individuals.

In conclusion, the present studies convincingly show that confronting an action crisis is associated with a high prevalence of cost benefit thinking. This signifies that an action crisis is accompanied by a mind set that is dissimilar from the typical mindset associated with the implemental phase in goal striving. Together, these results make impor tant theoretical contributions to the study of goal disengagement and action phase related mindsets.

\section{References}

Beckmann, J. (1998). Intrusive thoughts, rumination, and incomplete intentions. In M Kofta, G. Weary, \& G. Sedek (Eds.), Personal control in action: Cognitive and motivational mechanisms (pp. 259-278). New York: Plenum Press.
Beckmann, J., \& Heckhausen, H. (2008). Motivation as a function of expectancy and incentives. In J. Heckhausen, \& H. Heckhausen (Eds.), Motivation and action (pp. 99-136). (3rd edition). Cambridge, UK: Cambridge University Press.

Brandstätter, V. (2003). Persistenz und Zielablösung [Persistence and goal disengagement]. Göttingen, Germany: Hogrefe.

Brandstätter, H. (2007). The time sampling diary (TSD) of emotional experience in everyday life situations. In J. Allen, \& J. Coan (Eds.), The handbook of emotion elicitation and assessment (pp. 318-331). New York: Oxford University Press.

Brandstätter, V., Schüler, J., \& Frank, E. (2008). A cost-benefit analysis of doing exercise: How motivation, emotion, and behavior are affected. Unpublished manuscript, University of Zurich.

Brandtstädter, J. (2007). Das flexible Selbst: Selbstentwicklung zwischen Zielbindung und Ablösung [The flexible self: Self-development between commitment to and disengagement from goals]. Heidelberg: Elsevier/Spektrum Akademischer Verlag.

Brandtstädter, J., \& Rothermund, K. (2002). The life-course dynamics of goal pursuit and goal adjustment: A two-process framework. Developmental Review, 22, 117-150.

Brockner, J. (1992). The escalation of commitment to a failing course of action: Toward theoretical progress. Academy of Management Review, 17, 39-61.

Carver, C. S., \& Scheier, M. F. (1981). Attention and self-regulation: A control-theory approach to human behavior. New York: Springer-Verlag.

Carver, C. S., \& Scheier, M. F. (2005). Engagement, disengagement, coping, and catastrophe In A. J. Elliot, \& C. S. Dweck (Eds.), Handbook of competence and motivation (pp. 527-547). New York: Guilford.

Diederich, A. (2003). Decision making under conflict: Decision time as a measure of conflict strength. Psychonomic Bulletin E Review, 10, 167-176.

Emmons, R. A., \& King, L. A. (1988). Conflict among personal strivings: Immediate and long-term implications for psychological and physical well-being. Journal of Personality and Social Psychology, 54, 1040-1048.

Feather, N. T. (1962). The study of persistence. Psychological Bulletin, 59, 94-115.

Forgas, J. P. (1995). Emotion in social judgements: Review and a new affect infusion model (AIM). Psychological Bulletin, 117, 39-66.

Förster, J., Liberman, N., \& Higgins, E. T. (2005). Accessibility from active and fulfilled goals. Journal of Experimental Social Psychology, 41, 220-239.

Gollwitzer, P. M. (1990). In E. T. Higgins, \& R. M. Sorrentino (Eds.). Action phases and mind-sets. Handbook of motivation and cognition, 2. (pp. 53-92) New York: Guilford.

Gollwitzer, P. M. (2012). Mindset theory of action phases. In P. Van Lange, A. W. Kruglanski, \& E. T. Higgins (Eds.), Handbook of theories of social psychology (pp. 526-545). London: Sage Publications.

Gollwitzer, P. M., \& Sheeran, P. (2006). Implementation intentions and goal achievement: A meta-analysis of effects and processes. Advances in Experimental Social Psychology, 38, 69-119.

Goschke, T., \& Kuhl, J. (1993). Representation of intentions: Persisting activation in memory. Journal of Experimental Psychology: Learning, Memory, and Cognition, 19, 1211-1226.

Greenwald, A. G., McGhee, D. E., \& Schwartz, J. K. L. (1998). Measuring individual differences in implicit cognition: The Implicit Association Test. Journal of Personality and Social Psychology, 74, 1464-1480.

Gross, J. J., \& Thompson, R. A. (2007). Emotion regulation. Conceptual foundations. In J. J. Gross (Ed.), Handbook of emotion regulation (pp. 3-24). New York: Guilford.

Heckhausen, H. (1991). Motivation und action. New York: Springer.

Heckhausen, H., \& Gollwitzer, P. M. (1987). Thought contents and cognitive functioning in motivational versus volitional states of mind. Motivation and Emotion, 11, 101-120.

Heckhausen, J., Wrosch, C., \& Schulz, R. (2010). A motivational theory of life-span development. Psychological Review, 117, 32-60.

James, W. (1890). The principles of psychology. New York: Holt.

Jostmann, N. B., \& Koole, S. L. (2009). When persistence is futile: A functional analysis of action orientation and goal disengagement. In G. B. Moskowitz, \& H. Grant (Eds.), The psychology of goals (pp. 338-361). New York: Guilford.

Klinger, E. (1975). Consequences of commitment to and disengagement from incentives. Psychological Review, 82, 1-25.

Klinger, E. (1977). Meaning and void. Minnesota: University Press.

Kruglanski, A. W. (1996). Goals as knowledge structures. In P. M. Gollwitzer, \& J. A. Bargh (Eds.), The psychology of action: Linking cognition and motivation to behavior (pp. 599-618). New York: Guilford.

Kuhl, J. (1981). Motivational and functional helplessness: The moderating effect of state vs. action orientation. Journal of Personality and Social Psychology, 40, 155-170.

Kuhl, J. (1984). Volitional aspects of achievement motivation and learned helplessness: Toward a comprehensive theory of action control. In B. A. Maher, \& W. B. Maher (Eds.), Progress in experimental personality research, Vol. 13. (pp. 99-171) New York: Academic Press.

Kuhl, J., \& Kazén-Saad, M. (1988). A motivational approach to volition: Activation and de-activation of memory representations related to uncompleted intentions. In V. Hamilton, G. H. Bower, \& N. H. Frijda (Eds.), Cognitive perspectives on emotion and motivation. NATO ASI series D: Behavioral and social sciences, 44. (pp. 63-85) Dordrecht: Kluwer Academic Publishers.

Lewin, K. (1951). Field theory in social science. Chicago: The University of Chicago Press.

Mann, L., \& Janis, I. (1982). Conflict theory of decision making and the expectancyvalue approach. In N. T. Feather (Ed.), Expectations and actions: Expectancy-value models in psychology (pp. 341-364). Hillsdale, NJ: Lawrence Erlbaum Associates.

Marsh, R. L., Hicks, J. L., \& Bink, M. L. (1998). Activation of completed, uncompleted and partially completed intentions. Journal of Experimental Psychology: Learning, Memory, and Cognition, 24, 350-361.

Martin, D. E., \& Coe, P. N. (1997). Better training for distance runners (2nd ed.). Champaign, Ill: Human Kinetics.

Martin, L. L., \& Tesser, A. (1989). Toward a motivational and structural theory of ruminative thought. In J. S. Uleman, \& J. A. Bargh (Eds.), Unintended thought (pp. 306-326). New York: Guilford Press. 
Martin, L. L., \& Tesser, A. (1996). In R. S. WyerJr. (Ed.), Some ruminative thoughts. Advances in social cognition, 9. (pp. 1-47) Hilsdale, NJ: Erlbaum.

Martin, L. L., Tesser, A., \& McIntosh, W. D. (1993). Wanting but not having: The effects of unattained goals on thoughts and feelings. In D. M. Wegner, \& J. W. Pennebaker (Eds.). Handbook of mental control (pp. 552-572). Englewood Cliffs, NJ: Prentice-Hall.

Miller, N. E. (1944). In J. McV Hunt (Ed.), Experimental studies of conflict. Personality and the behavior disorders, 1. (pp. 431-465) New York: Ronald Press.

Miller, G. E., \& Wrosch, C. (2007). You've gotta know when to fold 'em. Psychological Science, $18,773-777$.

Nairne, J. S., Thompson, S. R., \& Pandeirada, J. N. S. (2007). Adaptive memory: Survival processing enhances retention. Journal of Experimental Psychology: Learning, Memory, and Cognition, 33, 263-273.

Nenkov, G. Y., \& Gollwitzer, P. M. (2012). Pre- versus postdecisional deliberation and goal commitment: The positive effects of defensiveness. Journal of Experimental Social Psychology, 48, 106-121.

Oettingen, G., \& Mayer, D. (2002). The motivating function of thinking about the future: Expectations versus fantasies. Journal of Personality and Social Psychology, 83, 1198-1212.

Sahakyan, L., \& Delaney, P. F. (2005). Directed forgetting in incidental learning and recognition testing: Support for a two-factor account. Journal of Experimental Psychology: Learning, Memory, and Cognition, 31, 789-801.

Stanislaw, H., \& Todorov, N. (1999). Calculation of signal detection theory measures. Behavior Research Methods, Instruments, E Computers, 31, 137-149.

Staw, B. M. (1997). The escalation of commitment: An update and appraisal. In Z. Shapira (Ed.), Organizational decision making. Cambridge series on judgement and decision making. (pp. 191-215) New York: Cambridge University Press.
Stevinson, C. D. \& Biddle, S. J. H. (1998). Cognitive orientations in marathon running and 'hitting the wall'. British Journal of Sports Medicine, 32, 229-235.

Trope, Y., \& Liberman, N. (2010). Construal-level theory of psychological distance. Psychological Review, 117, 440-463.

Tversky, A., \& Shafir, E. (1992). Choice under conflict: The dynamics of deferred decision Psychological Science, 3, 358-361.

Vallacher, R. R., \& Wegner, D. M. (1987). What do people think they're doing? Action identification and human behavior. Psychological Review, 94, 3-15.

Wattenmaker, W. D. (1999). The influence of prior knowledge in intentional versus incidental concept learning. Memory \& Cognition, 27, 685-698.

Weiner, B. (1985). Human motivation. New York: Springer

Wrosch, C. (2011). Self-regulation of unattainable goals and pathways to quality of life. In S. Folkman (Ed.), The Oxford handbook of stress, health, and coping (pp. 319-333) New York, NY: Oxford University Press.

Wrosch, C. Amir, E., \& Miller, G. E. (2011). Goal adjustment capacities, coping, and subjective well-being: The sample case of caregiving for a family member with mental illness. Journal of Personality and Social Psychology, 100, 934-946.

Wrosch, C., Miller, G. E., Scheier, M. F., \& de-Pontet, S. B. (2007). Giving up on unattainable goals: Benefits for health? Personality and Social Psychology Bulletin, 33, 251-265.

Wrosch, C., Scheier, M., Carver, C., \& Schulz, R. (2003). The importance of goal disengagement in adaptive self-regulation: When giving up is beneficial. Self and Identity, 2(1), $1-20$

Wrosch, C., Scheier, M. F., Miller, G. E., Schulz, R., \& Carver, C. S. (2003). Adaptive self-regulation of unattainable goals: Goal disengagement, goal reengagement, and subjective well-being. Personality and Social Psychology Bulletin, 29, 1494-1508. 